\title{
Photocatalytic decomposition of surfactants on nitrogen modified $\mathrm{TiO}_{2}$
}

\author{
Kamil Kuźmiński ${ }^{1}$, Antoni W. Morawski ${ }^{2}$, and Magdalena Janus ${ }^{1, *}$ \\ ${ }^{1}$ West Pomeranian University of Technology, Faculty of Civil Engineering and Architecture, Department of Sanitary \\ Engineering, al. Piastów 45, 70-311 Szczecin, Poland \\ ${ }^{2}$ West Pomeranian University of Technology, Faculty of Chemical Technology and Engineering, Institute of Inorganic \\ Chemical Technology and Environment Engineering, ul. Pułaskiego 10, 70-322 Szczecin, Poland
}

\begin{abstract}
In these studies advanced oxidation processes such as: photolysis, ozonation and photocatalysis for anionic and cationic surfactants decomposition were used. Nitrogen modified titanium dioxide and commercial $\mathrm{TiO}_{2}-\mathrm{P} 25$ were used for photocatalytic tests. UV-C lamp and different dose of ozone: $186,383,478$ and $563 \mathrm{mg} /\left(\mathrm{dm}^{3} \cdot \mathrm{h}\right)$ were used. The optimal system for anionic and cationic surfactants decomposition was connection of ozonation with UV-C irradiation.
\end{abstract}

\section{Introduction}

Surface active compounds used in households and numerous industrial sectors are one of the pollutants of surface water and groundwater. They constitute a serious water pollution, resulting in ecological threats to plants and animals, caused by the relatively long life of surfactants in water and low susceptibility to natural degradation. Consequently, the use of advanced oxidation methods based on, for example, the photocatalytic action of titanium dioxide particles and the oxidizing properties of ozone, appear to be a good and simple method for waste water purification. These processes are an effective alternative to conventional methods.

The primary and most valuable feature of photocatalysis is the ability to obtain complete mineralization of pollutants. Only effective access to the process requires access to light which may excite a photocatalyst. It has been proven that photocatalytic processes are ideal for the purification of contaminated water with organic compounds such as anionic surfactants sulphonated as sodium lauryl sulfate [1], sodium dodecylbenzenesulfonate [2] or sodium naphthalenesulfonate [3]. These processes have also been successfully used for nonionic decomposition [4] and cationic surfactants [5].

In heterogeneous photocatalysis using $\mathrm{TiO}_{2}$, the most effective oxidizing compounds are hydroxyl radicals. In aqueous environments they are generated by water oxidation, and are adsorbed on the surface of the photocatalyst. The oxidation agent of catalyst is positively charged electron holes $(\mathrm{h}+)$ formed in the $\mathrm{TiO}_{2}$ valence band a result of its excitation [6].

$$
\begin{gathered}
\mathrm{TiO}_{2}+h v \rightarrow h^{+}+e^{-} \\
h^{+}+\mathrm{H}_{2} \mathrm{O} \rightarrow \mathrm{OH}^{\cdot}+H^{+}
\end{gathered}
$$

In aerated systems, electrons (e $\mathrm{e}^{-}$) transferred to the conduction band can reduce dissolved oxygen to superoxide anion and continue to peroxide anion [7]:

$$
\begin{aligned}
e^{-}+\mathrm{O}_{2} & \rightarrow \mathrm{O}_{2}^{{ }^{-}} \\
e^{-}+\mathrm{O}_{2}^{--} & \rightarrow \mathrm{O}_{2}^{2-}
\end{aligned}
$$

It has been proven that photocatalysis can be an effective way of mineralizing surfactants, but combining it with the ozonation process can definitely accelerate the oxidation of pollutants. The general mechanism of oxidation of ozone in the aquatic environment can be divided into direct cycloaddition to multiple bonds (ozonolysis) [8], having a significant effect on the removal but not mineralization, and indirect mineralization by $\mathrm{O}_{3}$ decomposition products [9]. Ozone in the aquatic environment decomposes as a result of radical chain reactions, whose main products are $\mathrm{OH}$ radicals and $\mathrm{H}_{2} \mathrm{O}_{2}$ molecules.

The main aim of the study was to compare the photocatalytic efficiency of oxidation of anionic and cationic surfactants using nitrogen modified titanium dioxide $\left(\mathrm{TiO}_{2} / \mathrm{N}\right)$ obtained from the Institute of Inorganic Chemical Technology and Environment Engineering of the West Pomeranian University of Technology with commercially available $\mathrm{TiO}_{2}-\mathrm{P} 25$. In addition, the effect of changes in the ozonation process parameters in combination with UV photolysis and photocatalysis was determined.

\section{Experimental}

\subsection{Materials}

Sodium dodecylobenzenosulfonate and benzethonium chloride with concentration of $20 \mathrm{mg} / \mathrm{dm}^{3}\left(5.75 \cdot 10^{-5}\right.$ $\mathrm{mol} / \mathrm{dm}^{3} \quad \mathrm{NaDBS}, \quad 11.9 \quad \mathrm{mg} / \mathrm{dm}^{3} \quad \mathrm{pH} \quad$ 5.4; 
$4.46 \cdot 10^{-5} \mathrm{~mol} / \mathrm{dm}^{3} \mathrm{BtCl}$, TOC $16.2 \mathrm{mg} / \mathrm{dm}^{3}, \mathrm{pH} 5.2$ ) were used as model surfactants.

Commercial $\mathrm{TiO}_{2} \mathrm{P} 25$ was used as reference material with crystal size $26 \mathrm{~nm}$ and BET surface area $56 \mathrm{~m}^{2} / \mathrm{g}$, $75 \%$ of anatase and $25 \%$ of rutile phase [11]. At West Pomeranian University of Technology there is a possibility to produce nitrogen modified photocatalyst with high photocatalytic activity and high adsorption capacity. Nitrogen modified $\mathrm{TiO}_{2}$ was obtained from Institute of Inorganic Chemical Technology and Environment Engineering. It was choose as a second photocatalyst because there was no data about its activity during surfactants decomposition Moreover this is photocatalysts with different characteristic than commercial $\mathrm{TiO}_{2} \mathrm{P} 25$. It was prepared at E746 AutoLab (HEL Ltd) installation. $\mathrm{TiO}_{2}-\mathrm{N}$ average particle size amounted to $190 \mathrm{~nm}$, its BET surface area is $345 \mathrm{~m}^{2} / \mathrm{g}$, amorphous phase $67 \%$, anatase phase $30 \%$, rutile phase [10].

Zeta potential of $\mathrm{TiO}_{2} / \mathrm{N}$ and $\mathrm{TiO}_{2} \quad \mathrm{P} 25$ was determined for $\mathrm{pH} 3$ and 6 , because the reactions of photocatalytic decomposition of surfactants were conducted in these $\mathrm{pH}$ ranges. In Fig. 1 the relationship between $\zeta$-potential and solution $\mathrm{pH}$ value for tested photocatalysts was presented.

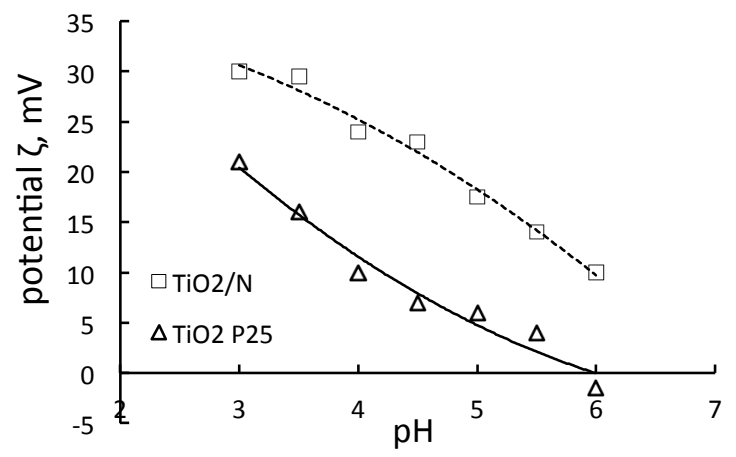

Fig. 1. Relationship between $\zeta$-potential and solution $\mathrm{pH}$ value for $\mathrm{TiO}_{2} / \mathrm{N}$ and $\mathrm{P} 25$.

\subsection{Advanced Oxidation Processes}

In Fig. 2 the installation for advanced oxidation processes is presented. The solution in a stainless steel reactor with an active capacity of $5 \mathrm{dm}^{3}$ was in the continuous flow provided by a peristaltic pump. The reactor was equipped with a low-pressure UV-C (25W) mercury lamp emitting almost all energy at $253.7 \mathrm{~nm}$ (TMA, Poland). Ozone was produced in the O3PRO DRP-30.7VW generator (Prozonex, Poland), powered by an oxygen concentrator (Everflo, Phillips) and pressed into the bottom of the UV-C reactor and then distributed evenly through the diffuser. The ozone concentration was measured in real time on the conduit connecting the $\mathrm{O}_{3}$ generator to the UV-C reactor via a photometric gas ozone analyzer (BMP 964, BMT Messtechnik GMBH, Germany) with a measurement range of $0-300 \mathrm{~g} / \mathrm{Nm}^{3}$. The concentration of total organic carbon (TOC) was determined using the Multi N/C 2100S analyzer (Analytik Jena AG, Germany).

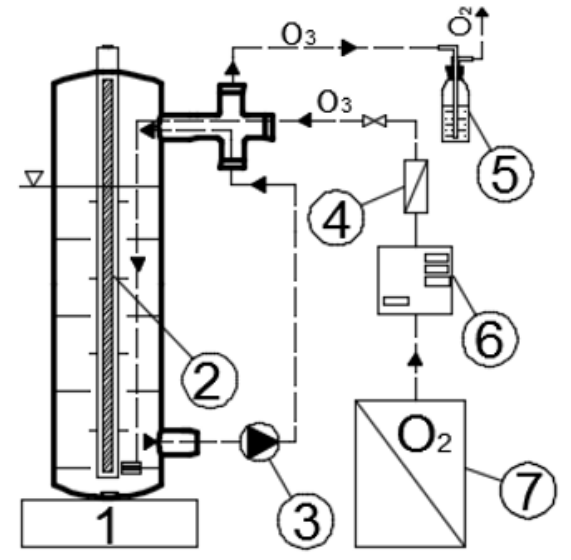

Fig. 2. Scheme of installation for AOPs (1 - magnetic stirrer, 2 - UV-C lamp, 3 - peristaltic pump, 4 - ozone analyzer, 5 - KI scrubber, 6 - ozone generator, 7 - oxygen concentrator).

The initial concentration of surfactants in aqueous solutions was $20 \mathrm{mg} / \mathrm{dm}^{3}\left(5.75 \cdot 10^{-5} \mathrm{~mol} / \mathrm{dm}^{3} \mathrm{NaDBS}\right.$; $\left.4.46 \cdot 10^{-5} \mathrm{~mol} / \mathrm{dm}^{3} \mathrm{BtCl}\right)$. Prior to photocatalysis $(\mathrm{TiO} 2+$ UV) and photocatalytic ozonation $(\mathrm{TiO} 2+\mathrm{UV}+\mathrm{O} 3)$ processes, adsorption was carried out in the dark for 30 minutes (to obtain an adsorption equilibrium). The concentration of the total organic carbon (TOC) after this step was treated as the initial concentration $\left(\mathrm{TOC}_{0}\right)$. UV$\mathrm{C}$ (UV) photolysis, ozone $\left(\mathrm{O}_{3}\right)$ photolysis, UV-C photolysis with simultaneous ozone (UV + O3) was also performed to compare the effectiveness of the investigated processes. During the photocatalytic reaction, oxygen was injected into the reactor (100 $\left.\mathrm{dm}^{3} / \mathrm{h}\right)$.

\section{Results and discussion}

\subsection{Ozonation and UV light irradiation}

For decomposition of anionic and cationic surfactants the ozone and UV-C light irradiation were used. As it can be observed in Table 1 under UV light irradiation the increasing of ozone dose (from 186 to $563 \mathrm{mg} /\left(\mathrm{dm}^{3} \mathrm{~h}\right)$ ) increased the surfactants decomposition. Ozone alone removed only $9 \%$ of $\mathrm{NaDBS}$ and $20 \%$ of $\mathrm{BtCl}$. The initial $\mathrm{pH}$ of reaction solution is acidic and in this condition mainly ozonolization occur, but the oxidation of $\mathrm{BtCl}$ is faster than $\mathrm{NaDBS}$, because $\mathrm{O}_{3}$ reacts with chlorine anions according to equations 5-6:

$$
\begin{gathered}
\mathrm{H}^{+}+\mathrm{O}_{3}+\mathrm{Cl}^{-} \leftrightarrow \mathrm{HO}_{3} \mathrm{Cl} \\
\mathrm{HO}_{3} \mathrm{Cl} \rightarrow \mathrm{HOCl}+\mathrm{O}_{2}
\end{gathered}
$$

As a result hypochlorous acid is formed, widely used as a bleaching agent and disinfectant due to its high oxidizing potential. Another reason could be the electrophilic behavior of the ozone molecule relative to the carbon atoms in the $\alpha$ position to the oxygen atoms (at $\mathrm{pH}<6$ ). As a result of the transfer of the hydrogen atom to the $\mathrm{O}_{3}$ molecule, a carbonic cation is formed, stabilized by resonance with the oxygen atom. 
Table 1. Removal of TOC content in NaDBS and BtCl solution during advanced oxidation processes after $1 \mathrm{~h}$, values of dosed ozone are shown in brackets $\left(\mathrm{mg} /\left(\mathrm{dm}^{3} \mathrm{~h}\right)\right)$.

\begin{tabular}{|c|c|c|}
\hline & $\begin{array}{c}\text { \% removal } \\
\text { of NaDBS }\end{array}$ & $\begin{array}{c}\text { \% removal } \\
\text { of BtCl }\end{array}$ \\
\hline $\mathrm{UV}-\mathrm{C}$ & 11 & 14 \\
\hline $\mathrm{O}_{3}(478)$ & 9 & 20 \\
\hline $\begin{array}{c}\mathrm{UV}-\mathrm{C}+\mathrm{O}_{3} \\
(186)\end{array}$ & 86 & 82 \\
\hline $\begin{array}{c}\mathrm{UV}-\mathrm{C}+\mathrm{O}_{3} \\
(383)\end{array}$ & 96 & 84 \\
\hline $\begin{array}{c}\mathrm{UV}-\mathrm{C}+\mathrm{O}_{3} \\
(478)\end{array}$ & 97 & 88 \\
\hline $\begin{array}{c}\mathrm{UV}-\mathrm{C}+\mathrm{O}_{3} \\
(563)\end{array}$ & & \\
\hline
\end{tabular}

To the cation, the previously formed $\mathrm{HO}_{3}^{-}$may be attached to form a $\mathrm{HO}_{2}^{-}$fast reaction with $\mathrm{H}^{+}$followed by removal of one oxygen atom, which is the product of $\mathrm{H}_{2} \mathrm{O}_{2}$. This follows, in line with the course of the following reaction, forms $\mathrm{OH}$ radicals with the ozone [13]:

$$
2 \mathrm{O}_{3}+\mathrm{H}_{2} \mathrm{O}_{2} \rightarrow 2 \mathrm{OH}^{\circ}+3 \mathrm{O}_{2}
$$

Under $\mathrm{pH}$ higher than 7 the $\mathrm{OH} \bullet$ radicals are produced (equations 8-10) [9]:

$$
\begin{gathered}
\mathrm{O}_{3}+\mathrm{OH}^{-} \rightarrow \mathrm{O}_{2}^{{ }^{-}}+\mathrm{HO}_{2}^{\cdot} \\
\mathrm{O}_{3}+\mathrm{HO}^{\cdot} \rightarrow \mathrm{O}_{2}+\mathrm{HO}_{2}^{\cdot} \leftrightarrow \mathrm{O}_{2}^{\cdot-}+\mathrm{H}^{+} \\
\mathrm{O}_{3}+\mathrm{HO}_{2}^{\cdot} \rightleftharpoons 2 \mathrm{O}_{2}+\mathrm{OH}^{\cdot}
\end{gathered}
$$

In Table 2 the $\%$ removal of surfactants with combined process of UV-C irradiation, ozonation and photocatalysis was presented. In Fig. 2 a) and b) the kinetics of surfactants decomposition under UV-C irradiation is presented.

Table 2. Photocatalytic decomposition of NaDBS and BtCl after $1 \mathrm{~h}$ of irradiation, in brackets are shown values of dosed ozone $\left(\mathrm{mg} /\left(\mathrm{dm}^{3} \mathrm{~h}\right)\right) \mathrm{T}$.

\begin{tabular}{|c|c|c|}
\hline & $\begin{array}{c}\text { \% removal } \\
\text { of NaDBS }\end{array}$ & $\begin{array}{c}\text { \% removal } \\
\text { of BtCl }\end{array}$ \\
\hline $\mathrm{UV}-\mathrm{C}-\mathrm{P} 25$ & 37 & 52 \\
\hline $\mathrm{UV}-\mathrm{C}-\mathrm{TiO}_{2} / \mathrm{N}$ & 20 & 55 \\
\hline $\begin{array}{c}\mathrm{O}_{3}(383)+ \\
\mathrm{UV}-\mathrm{C}-\mathrm{P} 25\end{array}$ & 89 & 83 \\
\hline $\begin{array}{c}\mathrm{O}_{3}(383)+ \\
\mathrm{UV}-\mathrm{C}-\mathrm{TiO}_{2} / \mathrm{N}\end{array}$ & 78 & 81 \\
\hline
\end{tabular}

The charge on the $\mathrm{TiO}_{2}$ surface with the opposite sign to the charge sign of the ionic surfactant will promote the adsorption of this surfactant to the catalyst. In surfactant solutions with acidic $\mathrm{pH}$, higher electrokinetic potential is characterized by $\mathrm{TiO}_{2} / \mathrm{N}$ and this is one of the main reasons for higher NaDBS desorption values.

As a result of the exposure process $(t=0)$ partial photocatalyst excitation occurs, resulting in first photolytic and photocatalytic reactions on the semiconductor surface. As a result of these reactions, the hydrocarbon chains of NaDBS molecules adsorbed on $\mathrm{TiO}_{2}$, resulting in partial desorption of these compounds, are depicted as increasing the concentration of TOC in the purified solution (Fig. 2). At a further stage of the process, $\mathrm{TiO}_{2}-\mathrm{P} 25$ is clearly a more effective semiconductor in the NaDBS oxidation by UV-C photocatalysis. This is due to the fact that $\mathrm{TiO}_{2}-\mathrm{P} 25$ is characterized by a significantly higher degree of surface hydroxylation [12], coupled with lower adsorption potential due to the lower zeta potential value, and therefore greater surfactant-free surface and better absorption of radiation. For higher efficiency in oxidation of NaDBS in solution volume by oxidation of water molecules to $\mathrm{OH}$ radicals.

a)

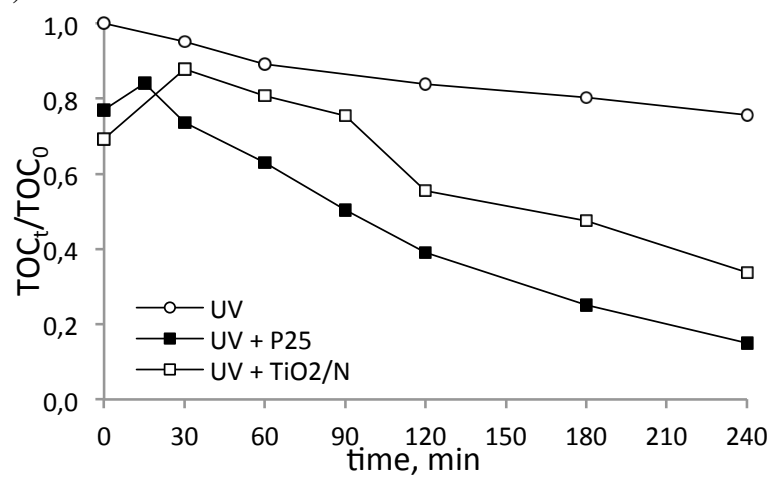

b)

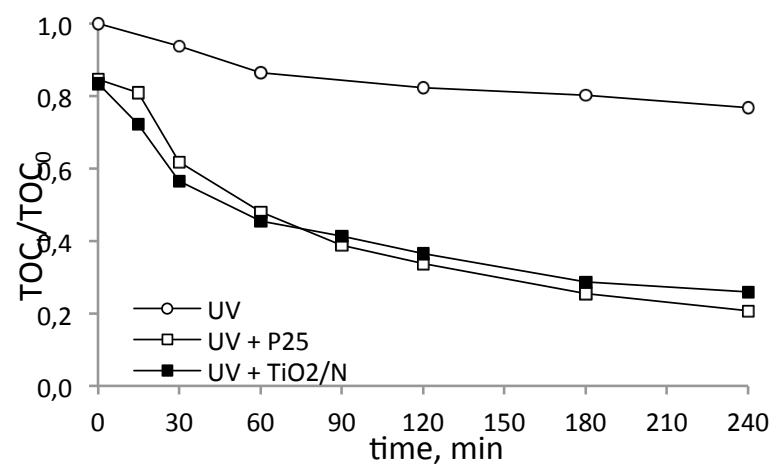

Fig. 3. Changing of TOC content in a) $\mathrm{NaDBS}$ and b) $\mathrm{BtCl}$ solutions as a function of time during UV-C photolysis and photocatalysis reactions using nitrogen modified $\mathrm{TiO}_{2}\left(\mathrm{TiO}_{2}-\right.$ $\mathrm{N}$ ) and $\mathrm{TiO}_{2} \mathrm{P} 25$ (time 0 - TOCt/TOC 0 after adsorption equilibrium process).

Photocatalytic surface reactions occur less often because the low-energy UV-C lamp induces a lower proportion of $\mathrm{TiO}_{2} / \mathrm{N}$ particles than $\mathrm{TiO}_{2}-\mathrm{P} 25$ because most of the active sites of the first are coated with 
anionic surfactant molecules. As a result, NaDBS oxidation through the electron hole in the valence band may lose its importance, making $\mathrm{TiO}_{2}-\mathrm{P} 25$ a better photocatalyst under given conditions.

\section{Conclusions}

As a result of the studies, it was found that the anionic NaDBS surfactant was more susceptible to mineralization using advanced oxidation methods than the cationic $\mathrm{BtCl}$ surfactant. The best condition for anionic and cationic surfactants decomposition is: UV-C light and ozone dosed in $478 \mathrm{mg} / \mathrm{dm}^{3} \cdot \mathrm{h}$. Under these conditions decomposition of NaDBS after $4 \mathrm{~h}$ of irradiation amounted to $96 \%$ and decomposition of $\mathrm{BtCl}$ amounted to $84 \%$.

\section{References}

1. O. Horváth, R. Huszánk, Photochem. Photobiol. Sci. 2, 960 (2003)

2. K. Kuźmiński, J. Grzechulska-Damszel, K. Zając, A.W. Morawski, M. Janus, Przem. Chem. 95, 2210 (2016)

3. P. Avetta, A. Bianco Prevot, D. Fabbri, E. Montoneri, L. Tomasso, Chem. Engin. J. 197, 193 (2012)

4. J. Perkowski, A. Bulska, W.K. Jóźwiak, Environ. Prot. Eng. 31, 61 (2005)

5. H. Hidaka, S. Yamada, S. Suenaga, Z. Jincai, J. Mol. Catal., (1990)

6. M.R. Hoffmann, S.T. Martin, W. Choi, D.W. Bahnemann, Chem. Rev. 95, 69 (1995)

7. Z. Zsilak, O. Fonagy, Environ. Sci. Pollut. Res. 21, 11126 (2014)

8. H.R. Einsenhauer, Water Res. 5, 467 (1971)

9. B. Kasprzyk-Hordern, M. Ziółek, J. Nawrocki, Appl. Catal. B. 46, 639 (2003)

10. M.D. Hernandez-Alonso, J.M. Coronado, A.J. Maira, J. Soria, V. Loddo, Appl. Catal. B. 39, 257, (2002)

11. A.V. Levanov, I.V. Kuskov, E.E. Antipenko, V.V. Lunin, Russ. J. Phys. Chem. A. 86, 757 (2012)

12. D.H. Giamalva, D.F. Church, W.A. Pryor, J. Amer. Chem. Soc. 108, 7678 (1986)

13. R. Munter, Proc. Eston. Acad. Sci. Chem. 50, 59 (2001) 